\title{
Life Cycle Cost versus Life Cycle Investment - A new approach
}

\author{
JOSÉ TORRES FARINHA ${ }^{1,2}$, HUGO NOGUEIRA RAPOSO ${ }^{1,2}$, DIEGO GALAR $^{3}$ \\ ${ }^{1}$ CEMMPRE - Centre for Mechanical Engineering, Materials and Processes, Univ. of Coimbra, \\ PORTUGAL \\ ${ }^{2}$ ISEC/IPC - Polytechnic Institute of Coimbra, PORTUGAL \\ ${ }^{3}$ LTU - Luleå University of Technology, SWEDEN
}

\begin{abstract}
The paper proposes a model for the life cycle of physical assets that includes the maintenance policy, because it has direct implications on the equipment's Return On Investment (ROI) and Life Cycle Cost; the developed model can be applied to any type of physical asset. The model is called Life Cycle Investment (LCI) instead of the traditional Life Cycle Cost (LCC). The paper proposes a new methodology based on the modified economic life cycle and lifespan methods by including the maintenance policy using maintenance Key Performance Indicators (KPI), namely Availability, based on the Mean Time Between Failures (MTBF) and the Mean Time To Repair (MTTR). The benefits (profits) that result from the asset's Availability must be balanced with the initial investment and the variable maintenance investment along its life, which has relation with the maintenance policy and the ROI.
\end{abstract}

Key-Words: - Physical Assets; Life Cycle Cost; LCC; Life Cycle Investment; ROI

Received: June 5, 2020. Revised: November 27, 2020. Accepted: December 15, 2020. Published: December 28, 2020.

\section{Introduction}

This paper presents a global approach to the life cycle of physical assets structured in two parts: The first one analyses the management of assets' global life cycle, from acquisition to withdrawal, usually called Life Cycle Cost (LCC); The second presents a new approach to assets' financial life cycle, based on econometric models, called Life Cycle Investment (LCI).

With the accelerated growth of the implementation of ISO5500X standards, as well as the maintenance norms, the importance of analysing carefully the asset's life cycle becomes a very relevant issue.

About this subject Farinha [9] presents an integrated approach of physical asset management emphasizing tools to manage the entire life cycle, comprising the following times and steps:

$t_{1}$ - Decision for acquisition;

$t_{2}$ - Terms of reference;

$\mathrm{t}_{3}$ - Market consultation;

$\mathrm{t}_{4}-$ Acquisition;

$\mathrm{t}_{5}$ - Commissioning;

$\mathrm{t}_{6}$ - Starting production / starting maintenance;

$\mathrm{t}_{7}$ - Economic / lifespan;

$\mathrm{t}_{8}$ - Renewal / withdrawal.

The author also shows the relations between the life cycle of physical assets, ISO 5500X standards (55000, 55001, 55002) and some maintenance standards, for example, NP4492 and others associated norms [9]. Figure 1 represents Farinha's graphical approach to the life cycle of physical assets including the standards.
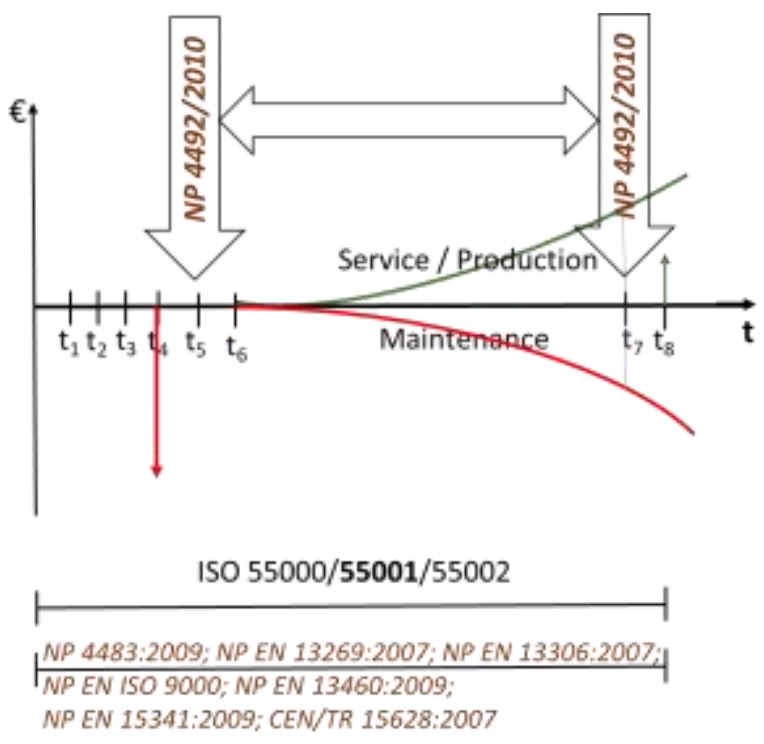

Figure 1-Times of a physical asset life cycle

As Figure 1 shows, to guarantee the service/production of the physical asset from acquisition to withdrawal, there is a continuous negative financial movement. Interestingly, however, the acquisition financial value is called investment, but the maintenance financial values along physical asset life cycle are called costs! Because of this contradiction, this paper uses the LCI instead of LCC. In fact, without ongoing investment along an asset's 
life cycle to support an adequate maintenance policy, it is not possible to guarantee the availability of the asset to meet its productive function. The econometric models used to evaluate the LCI consider all costs and benefits, from initial investment to withdrawal, including all the variables investments (usually called costs) to guarantee their normal functioning and Availability.

The paper is structured as follows:

- Section 2 synthesizes some relevant literature on an asset's life cycle and maintenance policies;

- Section 3 describes a global vision of a physical asset's life cycle and explains the life cycle cost versus the life cycle investment;

- Section 4 presents a simulation;

- Section 5 offers the conclusions.

\section{State of the Art on Asset's Life Cycle and Maintenance Policies}

Physical asset management is attracting increasing attention, especially after the publication of ISO $5500 \mathrm{X}$ standards (ISO 55000, ISO 55001, ISO 55002) and PAS 55. According to ISO 55000, the asset life is the period from "asset creation to asset end-of-life," and the life cycle corresponds to "the stages involved in the management of an asset". Woodward [1] says that "the life cycle cost of an item is the sum of all funds expended in support of the item from its conception and fabrication through its operation to the end of its useful life". To this he adds, "Life cycle costing is concerned with optimizing value for money in the ownership of physical assets by taking into consideration all the cost factors relating to the asset during its operational life".

According to Goh \& Sun [2], "the history of the application of Life Cycle Costing (LCC) began in the UK in the late 1950's." The authors conclude that "major improvements are necessary to make LCC comparable with common economic evaluation methods (e.g. benefit-to-cost ratio, net benefits and savings-to-investment ratio, for capital investment analysis related to buildings)". Lindholm \& Suomala [3] state that "Life Cycle Costing (LCC) is a way of thinking where attention is paid to the total costs that occur during a product's entire life cycle". The authors say that "an essential feature of LCC is cost monitoring during a product's life cycle". By the same way, Estevan \& Schaefer [4] argue that, "Life

\footnotetext{
${ }^{1}$ http://information.mcgsol.com/calculate-life-cyclecost-of-equipment, accessed on 2019.08.02
}

cycle costing is a powerful technique that supports the analytical processes by which managers can make the most cost-effective decisions on options presented to them at differing life cycle stages and at different levels of the life cycle cost estimate".

The United States Department of Energy (USDE) has a comprehensive life cycle cost definition: "the sum of all direct, indirect, recurring, nonrecurring, and other related costs incurred in the planning, design, development, procurement, production, operations and maintenance, support, recapitalization, and final disposition of real property over its anticipated life span for every aspect of the program, regardless of funding source."1.

Schuh, Jussen \& Optehostert [5] relate that, in the life cycle of products, "relevant information which can be used to assess the subsequent maintenance costs are requirements for product life cycle, e.g. service costs according to Total Cost of Ownership (TCO) as well as serviceability and maintainability of the product. Furthermore, organizational framework conditions for the service are defined in the planning phase."

Spickova \& Myskova [7] say that "The main goal of the Life Cycle Costing approach is to optimize life cycle costs of the assets or investment project without loss their performance", and the main costs of LCC are the following: investment (acquisition) costs; operation costs; maintenance costs; renewal costs; disposal (retirement) costs.

According to Kianian et al. [6], "Life Cycle Costing (LCC) was initially used by US Defence Department to seek optimal costs for acquiring, owing and operating an equipment during its useful life (also including any disposal costs)". The same authors emphasize that "these cost calculation methods usually do not include the three performance parameters (quality, productivity and availability) of the Overall Equipment Efficiency (OEE) measure, or lost profit, although Life Cycle Profit (LCP) were introduced already 1983 in literature".

Bengtsson \& Kurdve [8] present an LCC analysis of machining equipment in a Swedish company and discuss the Life Cycle Profit (LCP). The authors state that a company with a low LCC, does not necessarily have a high Life Cycle Profit (LCP). LCC is centred on the costs; however, if the asset's owner is a company, the LCC must be analysed simultaneously with the benefits, i.e., the physical assets' production results, suggesting that the asset's life cycle must be seen from an investment point of view. The authors also present theory on LCC and LCP; they add that, 
"there are a number of different options in working to achieve a high LCP" - "reducing LCC can be one option; however, sometimes it might be of value to increase LCC in order to reduce or eliminate losses that will increase LCP more than the increases in LCC".

In his recent book, Farinha [9] presents a global view of the life cycle of physical assets, including some tools to manage their entire life cycle, integrating the ISO 5500X, as well as the relations between maintenance policies and the LCC.

According to Ljiljana, Dragutin \& Zelimir [10], "Asset Management is a relatively new discipline that provides methods and tools for effective management of Physical Assets to maximize their utilization during entire Life Cycle. Asset Management evolved from Maintenance Management to provide a holistic approach to manage the life of a physical asset. This management is important for the performance of any organization, particularly Physical Asset intensive organizations". Today, it is recognized that asset governance is a key point for leading role in the development and implement asset management in the company and it is evidence in PAS 55 and the ISO 55000 standards.

Katicic, Lisjak \& Dulcic [13] say that physical asset management evolved from maintenance management to provide a holistic view for the management of the life of physical assets. The authors also mention that physical asset governance is a key point in the development and implementation of asset management in the ISO 5500X standards.

Stimie \& Vlok [11] propose a mechanism that can assist Physical Asset Management (PAM) practitioners and academics with the early detection and management of PAM Strategy Execution Failure (PAMSEF). The mechanism, a "Physical Asset Management Strategy Execution Enforcement Mechanism" (PAMSEEM), is a double-loop feedback system consisting of four iterative phases, four major decisions, and a number of implementation processes or steps.

The relevance of evaluating the life cycle of physical assets managed by Eicher [12] in the following way: "Investing in hospital infrastructure is not just a financing activity. It is important to consider the whole life cycle of an asset. For example, it is necessary to think about the operating life of an asset before building it, because this can influence investment costs and follow-up costs substantially".

Banyani \& Then [14] present a study showing how physical facilities management can be perceived at different levels of maturity based on personal judgement. They note the lack of a tool to assess maturity levels and propose an Integrated Feeder Factors Framework (I3F) as a yardstick. In the same way, Volker, Telli \& Ligtvoet [15] mention that an asset management system for the transportation sector requires system-level performance measures, models, and interoperable databases used by asset groups to make evidence-based decisions.

In the area of passenger urban transport, Hugo et al. [16], [17] discuss the relations between some maintenance KPIs, like MTTR, MTBF and availability, and the dimension of the reserve fleet. They use the Return On Investment (ROI) as the KPI to evaluate the relations between maintenance policy and the economic results.

According to the Center for Transportation Research and Education (CTRE), transportation agencies could benefit from the adoption of asset management principles. CTRE presents a guide to support transportation organizations in their implementation of a physical asset management program. It also presents a guide to the various levels of the transportation organization's maturity in undertaking the activities comprising the asset management framework. The levels of maturity presented are as follows [18]:

- Organizational goals and objectives;

- Inventory of pavements, bridges, and other major infrastructure assets;

- Knowledge of the age, condition, and deterioration of these assets;

- Availability of information to undertake life cycle cost analysis for all major asset types and asset classes;

- Information to undertake risk management analysis at the enterprise and program level;

- Information to develop the organization's financial plan to support investment;

- Development of investment strategies to manage the network for its whole life.

LCC is a commonly used concept mentioned in several standards, like the ISO 15663-1, Petroleum and natural gas industries - Life cycle costing - Part 1: Methodology. The work of Pais et al. [19] is in line with [9], as they include a diagnostic model on the state of organizations to help the implementation of ISO 55001.

Farinha [20] presents some econometric models to evaluate the LCC, including the withdrawal time for medical equipment.

Raposo et al. [21], [22] and [23] discuss the application of econometric models to LCC in an urban bus fleet based on maintenance costs, as well as their importance in a good management policy. The models include the influence of internal rate of 
return, as well as the price of fuel to the withdrawal time. These authors also discuss the influence of maintenance policy, namely the condition monitoring, in the LCC and the dimension of the fleet reserve.

Asiedu \& Gu [24] present an interesting life cycle cost analysis approach related to Life Cycle Assessment (LCA). The authors say LCA corresponds to a framework for the study of the impact of products and processes on the environment, and LCA is an environmental and energy audit that focuses on the entire life cycle of a product from raw material acquisition to withdrawal, including the environmental emission.

Durairaj, Nee \& Tan [25] review some methodological approaches; they outline a framework for a tool to evaluate eco-costs and present a cost effective eco-design for any product, in the ambit of a circular economy.

Kloepffer [26] emphasizes a model corresponding to a life cycle sustainability assessment (LCSA), that is the sum of the Life Cycle Assessment (LCA), plus the Life Cycle Cost (LCC), plus the Social Life Cycle Assessment (SLCA).

Sarma \& Adeli [27] emphasizes the relevance of LCC evaluation in all areas where physical assets are key. In the same way, Frangopol \& Liu [28] present a paper on maintenance and the management of civil infrastructure based on condition monitoring, including LCC. They note that most existing maintenance systems are based on the LCC minimization, and they may not correspond to longterm structural performance.

Toniolo [29] presents some dimensions of sustainability addressed in international standards using a life cycle perspective. The objective of the standards is to support LCA professionals in identifying for each specific situation the standards that ought to be used and the methods required to support the life cycle concepts beyond the environmental aspects.

Favi, Campi and Germani [30] offer a comparative life cycle assessment of metal arc welding technologies using engineering design documentation. They do not evaluate the maintenance area but they refer to it as an important variable.

Hugo et al. [16] and [17] demonstrate how a condition monitoring maintenance policy based on oil analysis influence the availability of urban buses.

Moubray [31] describes the importance of condition monitoring techniques and tools to increase the availability and the extending an asset's life cycle.
Rao [32] presents some important condition monitoring techniques and tools, including an analysis of cost-effective benefits.

Davies [33], in his book describes some techniques and tools for condition monitoring. The book emphasizes the economic justification and benefits of condition monitoring. It also discusses the variable investment in condition monitoring along the asset's life.

Nilsson \& Bertling [34] present two case studies of life cycle cost analysis for wind power systems using condition monitoring. The authors demonstrate that using condition monitoring results in improved maintenance planning; investing in these types of maintenance leads to increased availability and increased electricity production.

Fonseca, Farinha, and Barbosa [35] present a methodology, based on ant algorithm, demonstrating that in the maintenance management of any asset, both the policy and the maintenance logistics are keys to maximize the investment in the asset's life cycle.

Shina \& Jun [36] propose a general approach to a condition monitoring-based maintenance policy addressing several aspects of condition-based maintenance: definitions, related international standards, procedures, and techniques.

Wang [37] suggests a prognosis model for wear prediction based on oil monitoring; the author reports the development of a wear prediction model based on stochastic filtering and hidden Markov theory.

Simões et al. [38] present a state of the art hidden Markov model for predictive maintenance of Diesel engines, demonstrating the importance of investment in a maintenance policy based on oil analysis to maximize buses' availability, to maximize the number of passengers transported, and minimize the reserve fleet.

Yam et al. [39] propose an intelligent predictive decision support system for Condition-Based Maintenance (CBM). The authors develop an intelligent predictive decision support system for CBM, adding the capability of intelligent conditionbased fault diagnosis and the capacity to predict the trend of equipment deterioration. The approach was used as input to an integrated maintenance management system to pre-plan and pre-schedule maintenance work, to reduce inventory costs for spare parts, to cut down unplanned forced outage, and to minimize the risk of catastrophic failure. The success of the approach demonstrates the importance of investing in the right maintenance policy to maximize the equipment's life cycle.

Lebold et al. [40] review vibration analysis methods for gearbox diagnostics and prognostics. In fact, almost all equipment has vibrations; so, 
vibration analysis is one of the most important techniques to maximize the life cycle of assets.

Aherwar \& Khalid [41] review vibration analysis technique for gearbox diagnosis. Vibration signal analysis is widely used in the detection of faults in rotating machinery. The authors relate the importance of the maintenance policy to the equipment's life cycle.

Tchomeni \& Alugongo [42] present an experimental diagnosis of multiple faults on a rotorstator system using Fast Fourier Transform and wavelet scalogram, researching multiple fault detection for a rotating shaft using a time-frequency method; this approach permits to maximize the life cycle of this type of equipment.

LCC can be seen from the perspective of the consumer or investor. For the first, it signifies a cost; for the second, it represents an initial investment and a variable investment along the equipment's life cycle. For the first, it follows the asset's use and the maintenance policy recommended by the manufacturer; for the second, it tries to maximize the production capacity of the asset by investing in maintenance policies (i.e., condition monitoring, predictive maintenance, among others) that permit the investment to be maximized.

If "the life cycle cost of an item is the sum of all funds expended in support of the item from its conception and fabrication through its operation to the end of its useful life" [1], then, determining the LCC is an impossible exercise for the end user, because the person who purchases the equipment only knows the selling value and monetary values ahead.

The production income and the investment in maintenance must have the objective of maximizing availability, but the traditional LCC concept does not use these last two variables, as seen in [1]. The main variable companies can manage to improve equipment profitability is maintenance. The right maintenance strategy will increase the asset's availability and, consequently, its profitability.

Other relevant approach can be found in [43].

\section{Physical Assets' Life Cycle Analysis}

\subsection{Life Cycle Cost}

There are several ways to evaluate the LCC; two of these are the lifespan and the economic life cycle.

\subsubsection{Lifespan}

The lifespan ends when the maintenance costs overpass the maintenance costs plus the capital amortization of a new equivalent asset [9]. To calculate the lifespan, it is necessary to collect the historical cost data of the asset, as shown in Table 1 and Figure 2. In this theoretical example, the equipment reaches the end of its useful life after six years. Usually, the lifespan is longer than the economic life cycle.

To analyse the lifespan, the following variables should be considered:

- Initial investment - acquisition value;

- Exploration - functioning and maintenance;

- Cessation value.

Table 1 - Determining the lifespan of a physical asset

\begin{tabular}{|c|c|c|c|c|c|c|c|c|}
\hline YEARS & 0 & 1 & 2 & 3 & 4 & 5 & 6 & 7 \\
\hline Acquisition & 1200,00 & & & & & & & \\
\hline Exploration & & 740,00 & 77000 & 840,00 & ran,as & 200,00 & 1800,00 & 2000,00 \\
\hline Present Value $\left(C_{\mathrm{v}}\right)$ & & $6 x s, 19$ & coals & $\cos 6 x_{2}$ & $73 \leq 03$ & $\$ 6,70$ & 1134,31 & 1342,03 \\
\hline Cessation $\left(V_{c a}\right)$ & & seg, 00 & 64900 & 440,00 & $2 \operatorname{ssan}$ & $x, 000$ & 0,00 & $a, \infty$ \\
\hline $\begin{array}{l}\text { Present Value } \\
\left(V_{a b}\right)\end{array}$ & & $814: 81$ & $54 \times 70$ & 349.29 & $18: 76$ & 47.64 & 0,00 & $0, \infty$ \\
\hline $\begin{array}{l}\text { Exploration + } \\
\text { Devaluation }\end{array}$ & & 1070,37 & 1311,45 & 1517.53 & 1731,27 & nog,06 & 2334,34 & 24203 \\
\hline
\end{tabular}

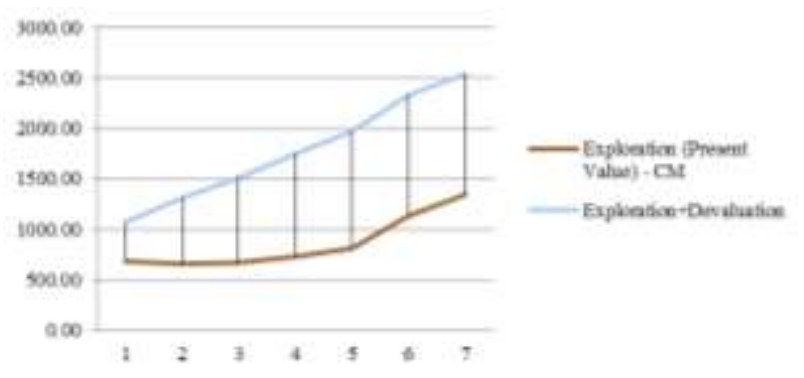

Figure 2 - Graph for analysis of lifespan

\subsubsection{Economic Life Cycle}

The end of economic life is the most rational time to withdraw an asset, minimizing the average total cost of operation, maintenance and capital immobilization. The economic life cycle method usually requires the conversion of all the financial movements of the physical asset to reach the present value, expressed by the Formula (1):

$$
P V=\sum_{t=1}^{N} \frac{F_{t}}{(1+I R R)^{t}}
$$

where

$P V$ is the present value,

$F_{t}$ is the financial movement, and

$I R R$ is the internal rate of return.

The following variables are considered in the analysis of the life cycle of a physical asset:

- Initial Investment (acquisition value) - II

- Functioning Present Value - FPV 
- $\quad$ Maintenance Present Value - MPV

- Benefit Present Value - BPV

In the traditional approach of the economic life cycle, under the concept of LCC, the benefits are considered null, as shown in Table 2.

The final global result $\left(G R_{n}\right)$ in year $n\left(B P V_{n}-A T C_{n}\right)$ can be represented by Formula (2):

$$
G R_{n}=\sum_{j=0}^{n} \frac{B_{j}}{(1+I R R)^{j}}-\sum_{j=0}^{n} \frac{F_{j}}{(1+I R R)^{j}}-\sum_{j=0}^{n} \frac{M_{j}}{(1+I R R)^{j}}
$$

where

$B_{j}$ is the value of benefit in year $j$,

$F_{j}$ is the value of functioning in year $j$, and

$M_{j}$ is the value of maintenance in year $j$.

Table 2 and Figures 3 and 4 show the simulation of an initial investment with variable costs of functioning and maintenance over 20 years. The interest rate considered is $25 \%$. The variables mentioned in the table, corresponding to the preceding considerations, are the following:

- Time

- Initial Investment - II

- Functioning Present Value - FPV

- Maintenance Present Value - MPV

- Accumulated Total Costs $(\mathrm{ATC}=\mathrm{FPV}+\mathrm{MPV})$

- Benefit Present Value - BPV

- Accumulated Total Benefits - ATB

Table 2 - Values of investment and functioning

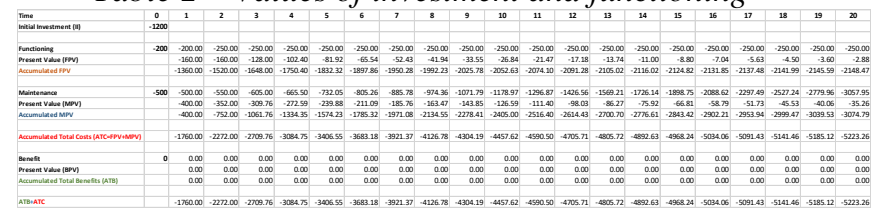

As can be seen, the final result of this approach has a negative financial movement, because it is based only on the costs.

About this subject, the references [9], [16] and [17] are very relevant.

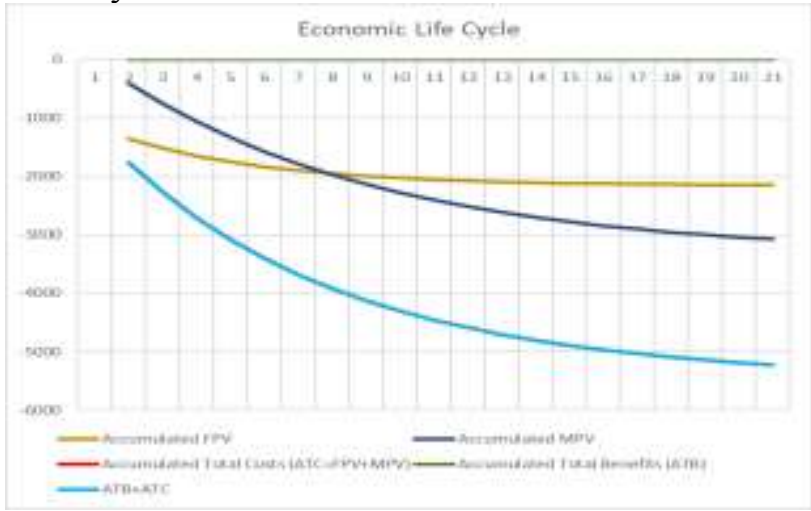

Figure 3 - Investment, functioning and maintenance

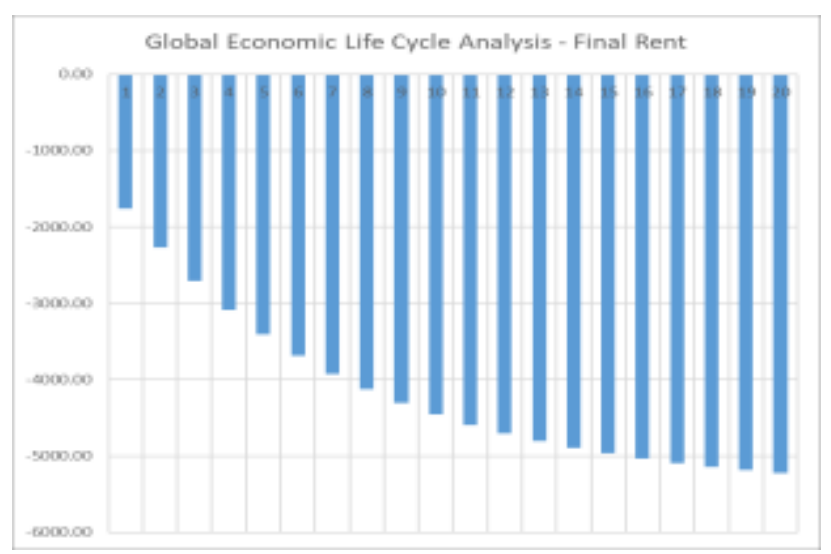

Figure 4 - Investment, functioning and maintenance

\subsection{Life Cycle Investment}

Investment and costs generally mean different things: the initial cost of a physical asset is called investment, but the remaining values along its life are usually called costs. It is important to clarify these concepts and to name the initial cost the initial investment and to name the remaining values along time as variable investments. This, in turn, suggests the need to change the acronym LCC to LCI (Life Cycle Investment) if the asset is used for industrial production.

Some maintenance KPI must be considered in industrial production companies, because the expected productivity of the equipment depends on them, namely the Availability.

The profits (benefits) are directly related with Availability: The benefits must be calculated considering that the equipment need downtime for maintenance, and the downtime duration is directly related to the maintenance policy, measured through the Mean Time To Repair (MTTR) - the lower MTTR the maximum Availability.

The non-productive time necessary to perform maintenance, both planned and non-planned, depends on the maintenance policy, including the following options:

- Planned maintenance

$$
\begin{array}{cl}
\circ & \text { Scheduled } \\
\circ & \text { Condition monitoring } \\
& \quad \text { Predictive }
\end{array}
$$

- Non-planned maintenance

The variable that usually measures the maintenance downtime is the Time To Repair (TTR), generally evaluated by its mean, i.e., the MTTR. The time of good functioning is usually called the Time Between Failures (TBF), usually evaluated by its mean, i.e., the Mean Time Between Failures (MTBF). Based on these two KPI, the Availability can be calculated using Formula (3): 


$$
A=\frac{M T B F}{M T T R+M T B F}
$$

However, when there is a fault, there may be a time interval between the fault communication and the technician intervention. This time is usually called Waiting Time (WT), generally evaluated by its mean, i.e., Mean Waiting Time (MWT). If this variable is considered in Formula (3), the new Availability evaluation, at time $j$, is done by Formula (4):

$$
A_{j}=\frac{M T B F_{j}}{M W T_{j}+M T T R_{j}+M T B F_{j}}
$$

Under this perspective, the Formula (2) can be upgraded to include Availability, that is multiplied by the total benefits $\left(B_{j}\right)$, because the useful time for production only happens when the physical asset has Availability. The Formula (5) includes this new variable:

$$
\begin{aligned}
& G R_{n}=\sum_{j=0}^{n} \frac{B_{j} * A_{j}}{\left(1+I R R_{j}\right)^{j}}-\sum_{j=0}^{n} \frac{F_{j}}{\left(1+I R R_{j}\right)^{j}}- \\
& \sum_{j=0}^{n} \frac{M_{j}}{\left(1+I R R_{j}\right)^{j}}-\sum_{j=0}^{n} \frac{N_{j}}{\left(1+I R R_{j}\right)^{j}}+\sum_{j=0}^{n} \frac{I_{j}}{\left(1+I R R_{j}\right)^{j}}(5)
\end{aligned}
$$

where

$$
\begin{aligned}
& B_{j} \text { is the value of benefit in year } j \\
& A_{j} \text { is the availability in year } j \\
& F_{j} \text { is the value of functioning in year } j \\
& M_{j} \text { is the value of maintenance in year } j \\
& N_{j} \text { is the value of non-production in year } j \\
& \text { and }
\end{aligned}
$$$$
I_{j} \text { is the value of the physical asset in year } j
$$

If the variable $A_{j}$ from Formula (4) is inserted into Formula (5), this results in Formula (6):

$$
\begin{aligned}
& G R_{n}=\sum_{j=0}^{n} \frac{B_{j}{ }^{*} \frac{M W T_{j}+M T T R_{j}+M T B F_{j}}{\left(1+I R R_{j}\right)^{j}}}{\left(1+M_{j}\right.}+\sum_{j=0}^{n} \frac{N_{j}}{\left(1+I R R_{j}\right)^{j}}+ \\
& \sum_{j=0}^{n} \frac{F_{j}}{\left(1+I R R_{j}\right)^{j}}+\sum_{j=0}^{n} \frac{I_{j}}{\left(1+I R R_{j}\right)^{j}}+ \\
& \sum_{j=0}^{n} \frac{I_{j}}{\left(1+I R R_{j}\right)^{j}}
\end{aligned}
$$

In addition, if we consider the values of nonproduction related to the unavailability of the physical asset, the variable $N_{j}$ may be evaluated using the Formula (7):

$N_{j}=B_{j} *\left(1-A_{j}\right)=B_{j} *\left(1-\frac{M T B F_{j}}{M W T_{j}+M T T R_{j}+M T B F_{j}}\right)$

By substituting the variable $N_{j}$ of Formula (7) into Formula (6), we get:

$$
\begin{aligned}
& G R_{n}=\sum_{j=0}^{n} \frac{B_{j} * \frac{M T B F_{j}}{M W T_{j}+M T T R_{j}+M T B F_{j}}}{\left(1+I R R_{j}\right)^{j}}+\sum_{j=0}^{n} \frac{F_{j}}{\left(1+I R R_{j}\right)^{j}}+ \\
& \sum_{j=0}^{n} \frac{M_{j}}{\left(1+I R R_{j}\right)^{j}}+\sum_{j=0}^{n} \frac{B_{j *}\left(1-\overline{M W T_{j}+M T T R_{j}+M T B F_{j}}\right)}{\left(1+I R R_{j}\right)^{j}}+ \\
& \sum_{j=0}^{n} \frac{I_{j}}{\left(1+I R R_{j}\right)^{j}}
\end{aligned}
$$

Formula (8) includes the initial investment and the variable maintenance annual investments along the asset's life, giving the global result that a company may expect from the asset's life cycle from an investment perspective.

\section{Case Study Simulation}

This section uses the developed models to demonstrate the importance of availability (based on the maintenance policy) in the LCI of a physical asset.

The next simulation considers an investment in a maintenance policy from which it is expected a positive return.

However, instead of this simulation, it can be done any type of simulation, where the Global Result can be any other: the model presented in the preceding section is general, being possible to use it to support any decision about the best combination between physical asset Availability and investment, considering the maintenance policy to reach the desired Availability.

Table 3 and Figures 5 and 6 consider the following values:

- Internal rate of return: 0.25

- Availability: 0.82

The variables mentioned in the table, corresponding to the preceding considerations, are as follows:

- Time

- Initial investment present value (IIPV)

- Functioning present value (FPV)

- Maintenance present value (MPV)

- Non-production present value (NPPV)

- Benefit present value (BPV)

Based on these values and using Equation (5), a positive cycle of results can be observed from the $4^{\text {th }}$ year to the $16^{\text {th }}$ year. 
Table 3 - Values of investment, functioning and benefits, with $A=0.82$

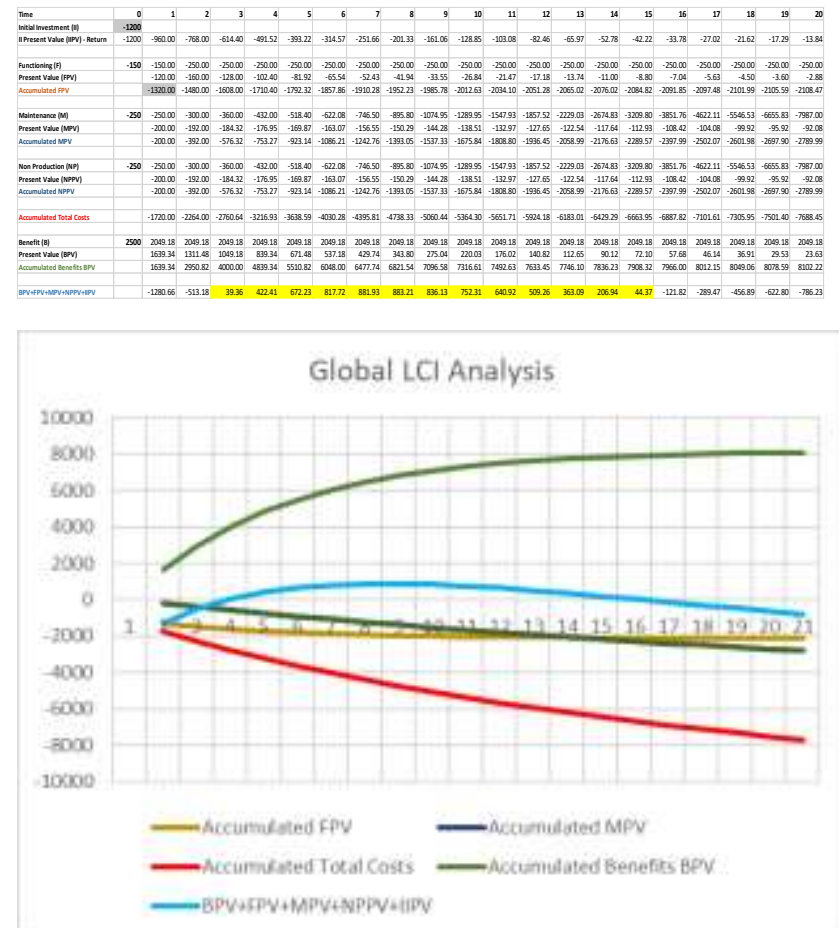

Figure 5 - Values of investment, functioning and benefits, according to Table 3

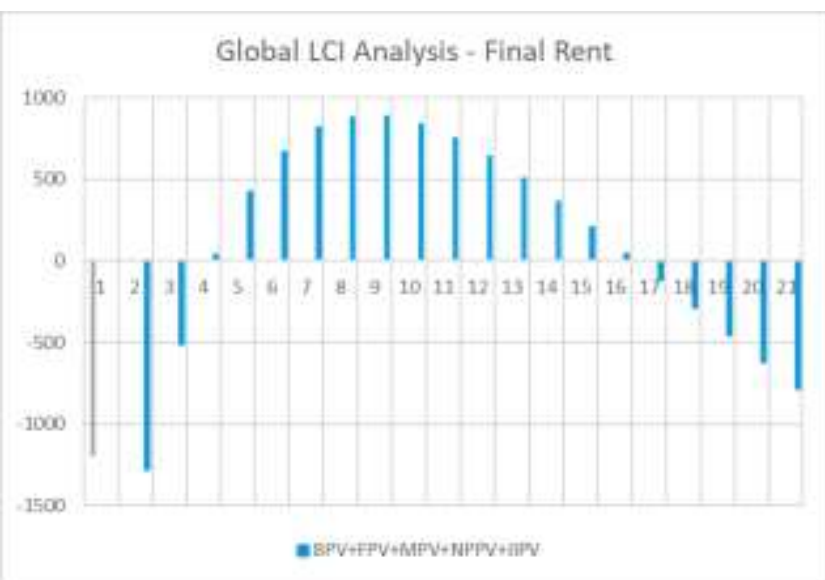

Figure 6-Annual financial results of physical asset investment, according to Table 3

Table 4 and Figures 7 and 8 consider the same values as Table 3 , but with a higher value for availability: 0.89 . Based on these values, a higher positive cycle of results can be observed from the $4^{\text {th }}$ year to the $20^{\text {th }}$ year - an increase of four years.

Table 4 - Values of investment, several costs, and benefits, with $A=0.89$

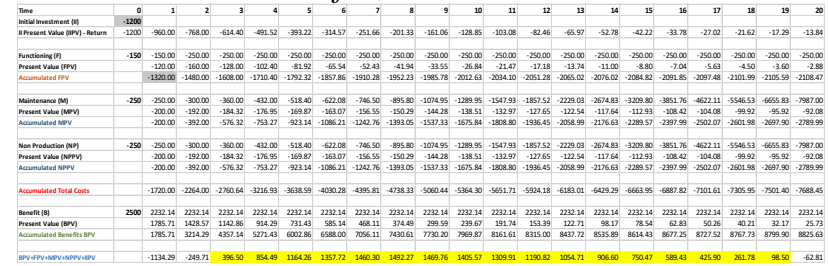

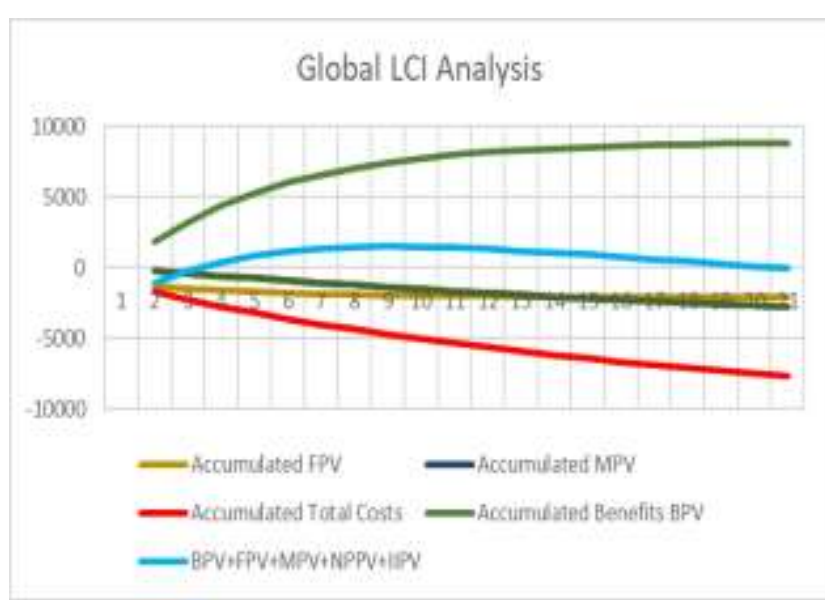

Figure 7 - Annual financial results of physical asset investment, according to Table 4

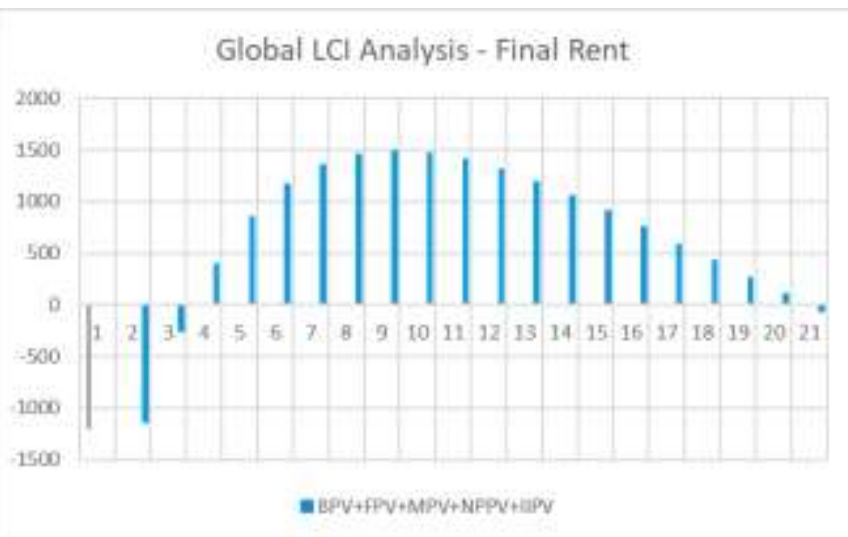

Figure 8-Annual financial results of physical asset investment, according to Table 4

As can be seen, maintaining all the other values and conditions of Table 3, i.e., values of acquisition, functioning, maintenance, and benefits, and with little increase in availability, i.e., from 0.82 to 0.89 , the profits (benefits) of the physical asset immediately increase by four years. This demonstrates the importance of investment in a good maintenance policy and the need to consider the concept of LCI instead of LCC.

\section{Conclusions}

Physical assets are very important investments, that must be carefully analysed, in order to evaluate which is the best maintenance policy for them, to reach the best Availability, as well as the best time to withdrawal. The paper presents an econometric model to make this evaluation, as well as a simulation with two situations of Availability.

As result it is proposed to change the traditional Life Cycle Cost (LCC) analysis concept to the Life Cycle Investment (LCI) analysis. The objective is to emphasize the importance of KPI related to the 
physical assets maintenance policy that maximize their Availability and, by consequence, their profits.

\section{References:}

[1] Woodward DG (1997). Life cycle costing Theory, information acquisition and application. International Journal of Project Management, vol. 15 , no. 6, pp. 335-344.

[2] Goh, BH \& Sun Y (2016). The development of life-cycle costing for buildings. Building Research \& Information, 44:3, 319-333, DOI: 10.1080/09613218.2014.993566

[3] Lindholm A, Suomala P (2002). Present and future of life cycle costing: reflections from Finnish companies. Vl. 54. Liiketa. Aikakauskirja: Finn. J. Bus. Econ. Pp282-292. https://www.researchgate.net/publication/228 742610_Present_and_future_of_life_cycle_co sting_reflections_from_Finnish_companies (Accessed on 2019.08.01)

[4] Estevan H \& Schaefer B (2017). Life Cycle Costing State of the art report. ICLEI - Local Governments for Sustainability, European Secretariat. (Ecoinstitut SCCL). http://www.sppregions.eu/fileadmin/user_upl oad/Life_Cycle_Costing_SoA_Report.pdf (accessed on 2019.08.01)

[5] Schuh G, Jussen P, Optehostert F (2019). Iterative Cost Assessment of Maintenance Services. 26 ${ }^{\text {th }}$ CIRP Life Cycle Engineering (LCE) Conference. ScienceDirect. Procedia CIRP 80 (2019) 488-493

[6] Kianian B, Kurdve M, Andersson C (2019). Comparing Life Cycle Costing and Performance Part Costing in Assessing Acquisition and Operational Cost of New Manufacturing Technologies. $26^{\text {th }}$ CIRP Life Cycle Engineering (LCE) Conference. ScienceDirect. Procedia CIRP 80 (2019) 428433 www.elsevier.com/locate/procedia

[7] Spickova M, Myskova R (2015). Costs Efficiency Evaluation using Life Cycle Costing as Strategic method. Business Economics and Management 2015 Conference, BEM2015. Available online at www.sciencedirect.com. Procedia Economics and Finance 34 (2015) 337-343. Doi: 10.1016/S2212-5671(15)01638-X

[8] Bengtsson M, Kurdve M (2016). Machining Equipment Life Cycle Costing Model with Dynamic Maintenance Cost. 23 ${ }^{\text {rd }}$ CIRP Conference on Life Cycle Engineering. Procedia CIRP 48 (2016) 102-107. doi: 10.1016/j.procir.2016.03.110
[9] Farinha JT (2018). Asset Maintenance Engineering Methodologies. CRC Press; $1^{\text {st }}$ edition (May 29, 2018). English. Printed in USA. ISBN-10: 1138035890. ISBN-13: 9781138035898.

[10] Ljiljana K, Dragutin L, Zelimir D (2014). Asset governance as strategy for physical asset. $7^{\text {th }}$ International Conference of the School of Economics and Business Conference Proceedings, 13.-14.09.2014., Sarajevo, Bosna i Hercegovina. Pp208-221. https://www.bib.irb.hr/728091

[11] Stimie JE, Vlok PJ (2016). A Mechanism for the Early Detection and Management of Physical Asset Management Strategy Execution Failure. South African Journal of Industrial Engineering November 2016 Vol 27(3) Special Edition, pp 158-173. http://dx.doi.org/10.7166/27-3-1651

[12] Eicher B (2016). Selection of asset investment models by hospitals: examination of influencing factors, using Switzerland as an example. International Journal of Health Planning and Management 2016; 31: 554-579. Published online 20 May 2016 in Wiley Online Library. wileyonlinelibrary.com. DOI: 10.1002/hpm. 2341

[13] Katicic L, Lisjak D, Dulcic Z (2014). Asset governance as strategy for physical asset. $7^{\text {th }}$ International Conference of the School of Economics and Business Conference Proceedings, 13.-14.09.2014., Sarajevo, Bosna i Hercegovina. Pp208-221. https://www.bib.irb.hr/728091

[14] Banyani MA, Then DSS (2014). A Model for Assessing the Maturity of Facility Management as an Industry Sector. CIB W070 International Conference in Facilities Management. Proceedings of CIB Facilities Management Conference "Using facilities in an Open World - Creating Value for all Stakeholders". 21-23 May Copenhagen. Pp99110.

[15] Volker L, Telli VDL, Ligtvoet A (2011). Developing a maturity model for infrastructural asset management systems. $10^{\text {th }}$ Conference on Applied Infrastructure Research - Infraday 2011. http://www.infraday.tuberlin.de/fileadmin/fg2 80/veranstaltungen/infraday/conference_2011 /papers_presentations/papervolker_vanderlei ligtvoet.pdf, accessed on 2019.04.14

[16] Raposo H, Farinha JT, Ferreira, LA, Galar D (2017). Dimensioning Reserve Bus Fleet using Life Cycle Cost Models and Condition Based 
/ Predictive Maintenance - a Case Study. Public Transport. Volume 10 Number 1. Springer Berlin Heidelberg. pp 1-22. DOI https://doi.org/10.1007/s12469-017-0167-X. Print ISSN 1866-749X. Online ISSN 16137159.

[17] Raposo H, Farinha JT, Ferreira LA, Galar D (2017). An integrated econometric model for bus replacement and spare reserve based on a condition predictive maintenance model. Maintenance and Reliability. Eksploatacja i Niezawodnosc - Maintenance and Reliability 2017; $\quad 19 \quad$ (3): $\quad 358-368$, http://dx.doi.org/10.17531/ein.2017.3.6. Pp358-368. ISSN 1507-2711.

[18] CTRE (2018). Importance of Maturity in Implementing Asset Management. CTRE, Iowa State University center, administered by the Institute for Transportation. http://www.ctre.iastate.edu/piarc/, accessed on 2018.05.15.

[19] Pais E, Raposo H, Meireles A, Farinha JT (2019). ISO 55001 - A Strategic Tool for the Circular Economy - Diagnosis of the Organization's State. Journal of Industrial Engineering and Management Science, Vol: 2018 Issue: 1. Article No: 5 Page: 89108 doi: https://doi.org/10.13052/jiems24461822.2018.005

[20] Farinha JMT (2011). Manutenção - A Terologia e as Novas Ferramentas de Gestão. MONITOR, Lisboa, Portugal. ISBN 978-9729413-82-7.

[21] Raposo H, Farinha JT, Fonseca I, Ferreira LA (2019). Condition Monitoring with Prediction Based on Diesel Engine Oil Analysis: A Case Study for Urban Buses. Volume 8, Issue 1. EISSN 2076-0825 Published by MDPI AG, Basel, Switzerland. Actuators $\quad 2019, \quad 8(1), \quad 14$; doi: $10.3390 /$ act 8010014

[22] Raposo H, Farinha JT, Fonseca I, Galar D (2019). Predicting condition based on oil analysis - A case study. Tribology International. Volume 135, July 2019, Pages 65-74 ISSN 0301-679X. PII: S0301679X(19)30049-0. Reference: JTRI 5582. DOI:

https://doi.org/10.1016/j.triboint.2019.01.041

[23] Raposo H, Farinha JT, Ferreira LA, Didelet F (2019). Economic life cycle of the bus fleet: a case study. Inderscience Enterprises Ltd. International Journal of Heavy Vehicle
Systems (IJHVS), Vol. 26, No. 1, 2019. Pp3154. DOI: 10.1504/IJHVS.2019.097109

[24] Asiedu Y, Gu P (1998). Product life cycle cost analysis: State of the art review. International Journal of Production Research, 36:4, 883908, DOI: 10.1080/002075498193444

[25] Durairaj SK, Nee AYC, Tan RBH (2002). Evaluation of Life Cycle Cost Analysis Methodologies. Corporate Environmental Strategy. Volume 9, Issue 1, February 2002, Pages 30-39. https://doi.org/10.1016/S10667938(01)00141-5

[26] Kloepffer W (2008). Life Cycle Sustainability Assessment of Products. Int J Life Cycle Assess. $13: \quad 89$. https://doi.org/10.1065/lca2008.02.376

[27] Sarma KC, Adeli H (2002). Life-cycle cost optimization of steel structures. Int. J. Numer. Meth. Eng 2002; 55:1451-1462. DOI: $10.1002 / \mathrm{nme} .549$

[28] Frangopol DM, Liu M (2007). Maintenance and management of civil infrastructure based on condition, safety, optimization, and lifecycle cost. Structure and Infrastructure Engineering, 3:1, 29-41, DOI: 10.1080/15732470500253164

[29] Toniolo S, Mazzi A, Mazzarotto G, Scipioni A (2019). International standards with a life cycle perspective: which dimension of sustainability is addressed? Int. J. of Life Cycle Assess. https://doi.org/10.1007/s11367-019-01606-w

[30] Favi C, Campi F, Germani M (2019). Comparative life cycle assessment of metal arc welding technologies by using engineering design documentation. Int J Life Cycle Assess (2019). https://doi.org/10.1007/s11367-01901621-x

[31] Moubray J (1997). Reliability-Centered Maintenance Second Edition. Industrial Press, Inc.; Second edition. ISBN-10: 0831131462. ISBN-13: 978-0831131463

[32] Rao BKN (1996). Handbook of Condition Monitoring. Elsevier Science. ISBN-10: 1856172341. ISBN-13: 978-1856172349

[33] Davies A (1997). Handbook of Condition Monitoring: Techniques and Methodology. Springer. ISBN-10: 0412613204. ISBN-13: 978-0412613203

[34] Nilsson J, Bertling L (2007). Maintenance Management of Wind Power Systems Using Condition Monitoring Systems - Life Cycle Cost Analysis for Two Case Studies. IEEE Transactions on Energy Conversion. Volume: 
22, Issue: 1. Pp223-229. DOI: 10.1109/TEC.2006.889623

[35] Fonseca I, Farinha JT; Barbosa FM (2014): "Maintenance planning in wind farms with allocation of teams using genetic algorithms". IEEE Latin America Transactions - Vol 12, Issue 6. September 2014. ISSN: 1548-0992. Pp1062-1070.

DOI: 10.1109/TLA.2014.6894001

[36] Shina J-H, Jun H-b (2015). On condition based maintenance policy. Journal of Computational Design and Engineering. Volume 2, Issue 2. $\mathrm{Pp}$ $119-127$. https://doi.org/10.1016/j.jcde.2014.12.006

[37] Wang W (2007) A prognosis model for wear prediction based on oil based monitoring. Journal of the Operational Research Society. 58:7, 887-893. https://doi.org/10.1057/palgrave.jors.2602185

[38] Simões A, Viegas J, Farinha JT, Fonseca I (2017). The state of the art of Hidden Markov Models for predictive maintenance of Diesel engines. Quality and Reliability Engineering International. WILEY-BLACKWELL. DOI:10.1002/qre. 2130

[39] Yam R, Tse P, Li L, Tu P (2001). Intelligent Predictive Decision Support System for Condition-Based Maintenance. Int $\mathrm{J}$ Adv Manuf Technol. 17: 383. https://doi.org/10.1007/s001700170173

[40] Lebold M, McClintic K, Campbell R, Byington C, Maynard K (2000). Review of Vibration Analysis Methods for Gearbox Diagnostics and Prognostics. Proceedings of the $54^{\text {th }}$ Meeting of the Society for Machinery Failure Prevention Technology, Virginia Beach, VA, May 1-4, 2000, p. 623-634. http://citeseerx.ist.psu.edu/viewdoc/summary ?doi $=10.1 .1 .462 .9240 \quad$ (accessed on 2019,07.31)

[41] Aherwar A, Khalid MS (2012). Vibration analysis techniques for gearbox diagnostics: a review. International Journal of Advanced Engineering Technology. IJAET/Vol. III/ Issue II/April-June, 2012/04-12. E-ISSN 0976-3945

[42] Tchomeni BX, Alugongo A (2019). Experimental diagnosis of multiple faults on a rotor-stator system by fast Fourier transform and wavelet scalogram. Vaal University of Technology, Mechanical Engineering Department, Vanderbijlpark, South Africa. ISSN PRINT 1392-8716, ISSN ONLINE 2538-8460.

https://doi.org/10.21595/jve.2018.19639
[43] E. Pais, J. T. Farinha, A. J. M. Cardoso, H. Raposo (2020). "Optimizing the Life Cycle of Physical Assets - a Review". WSEAS TRANSACTIONS on SYSTEMS and CONTROL. E-ISSN: 2224-2856. Volume 15, $2020 . \quad$ Pp417-430. DOI: $10.37394 / 23203.2020 .15 .42$

\section{Creative Commons Attribution}

\section{License 4.0 (Attribution 4.0 International, CC BY 4.0)}

This article is published under the terms of the Creative Commons Attribution License 4.0 https://creativecommons.org/licenses/by/4.0/deed.en US 